\title{
Editorial
}

\section{The Joint Forum: Initiatives by the BCBS, IAIS and IOSCO to combat money laundering and the financing of terrorism}

A process of deregulation and the liberalisation of the financial markets over the last several decades has resulted in the growing emergence of financial conglomerates. This period saw the initial dismantlement of specialisation that distinguished the various markets and their participants. Financial conglomerates provide a combination of banking, insurance and securities business within a single group. The growth in the number of financial conglomerates has increased the interdependency of the financial system in both domestic and international contexts. A financial conglomerate can jointly market different financial products within a core portfolio of activities at domestic and international level and easily distribute products through their business network. The risks a financial conglomerate pose are not new, but a more coordinated approach to the supervision of their activities between the respective regulators is considered necessary to reduce any disparities in their supervision. A large proportion of the work so far has centred on prudential regulation and supervision of financial conglomerates and especially on capital requirements and the concentration of risk across their business activities.

A significant proportion of the work on financial conglomerates has been undertaken by the Joint Forum, a group of technical experts, set up in 1996 to continue the work of the Tripartite Group whose responsibility was to examine supervisory issues governing those institutions. The
Joint Forum has, inter alia, a membership down from the following international supervisory bodies: the Basel Committee on Banking Supervision (BCBS), the International Organisation of Securities Commissions (IOSCO) and the International Association of Insurance Supervisors (IAIS). Its mandate is to investigate specific issues governing each sector of the financial system and the unique risks posed by financial conglomerates. The Joint Forum is also given a wide agenda to research issues of common interest to the three parent committees. First, it is required to study common issues, including risk management, corporate governance and different approaches to regulation and supervision. Secondly, it has a responsibility to develop guidance and principles of best practice that govern risk and implications of extreme exogenous shocks within the regulated sectors. Thirdly, it is required to set up gateways for sharing information between the respective regulators and to prescribe principles of best practice for the supervision of financial conglomerates.

In the 21 st century, a more pressing concern has been initiatives by the various international supervisory standard setters to combat money laundering and the financing of terrorism. In the Joint Forum's most recent publication the vulnerability of financial conglomerates is highlighted as well as the inconsistencies that exist between the regulated sectors and the work done so far to reduce the disparities 
between them. This joint note highlights the importance of reducing the differences that exist between the regulated sectors to prevent criminal proceeds flowing to the institutions governed by the least stringent standards. It also points out the importance of attaining a level playing field in the standards the financial sectors adopt to combat money laundering and terrorist funding to avoid anomalies in regulatory standards from being exploited. Moreover, a level playing field would ensure that compliance costs to combat money laundering and the financing of terrorism are distributed proportionately between the three financial sectors.

The joint note provides an overview of the measures taken by the three parent supervisory bodies to combat money laundering and the financing of terrorism. A significant proportion of the measures introduced by them build on the work of the Financial Action Task Force (FATF) recommendations to combat these activities. These recommendations are also a part of the methodology used by the International Monetary Fund (IMF) and World Bank to measure international compliance with those standards to combat money laundering and the funding of terrorism. While the banking sector has the most detailed standards, the IMF and World Bank have suggested that the international community has not implemented the recommendations consistently. The joint note does provide some comfort by highlighting that large anomalies do not exist between the three sectors. However, inconsistencies are present which could be exploited if a financial institution in one sector is allowed to sell products from another with less stringent compliance standards. The joint note does not recommend mirror image standards of compliance across the three financial sectors but it does highlight the importance of a groupwide system of control to monitor the identity of customers that use their financial services. The joint note points out the concern that less stringent standards can mean lower compliance costs, thus making it cheaper to do business in one sector than in another which implements more stringent rules. This ultimately undermines the goal of a level playing field across all three financial sectors where financial services can be sold across sectors. The Joint Forum advocates the need for a consolidated approach to implement customer due diligence requirements to avoid applying different requirements to the same person. This requires clear gateways within the group to ensure information about a person in one part is accessible in another. Following the overall assessment by the Joint Forum, the joint note then outlines the work undertaken so far in each sector of the financial system and the vulnerabilities that need to be addressed.

The joint note points out that banks are exposed to money laundering in a number of ways. For example, customers that use a false 'front' to hide their identity; the confidentiality that underpins private banking; customers who are 'politically exposed persons'; the reliance given to the due diligence of a third-party; a lack of knowledge about the business it undertakes with a corresponding bank. The BCBS issued guidance on the subject of customer due diligence in 2001 to reduce the likelihood of banks acting as conduits for the proceeds of crime and terrorism. The Joint Forum reiterates the recommendations made by them, together with more rigorous standards of their own on due diligence for higher-risk areas. For example, senior management should be consulted when banks enter business with high-risk customers; the bank should refuse to do business with a person who cannot be identified; and due diligence should be enhanced for private banking business. Furthermore, banks need to ensure rigorous systems and controls are 
in place to verify the identity as well as the information provided by a person who acts in the capacity of an 'introducer' for a customer.

The IAIS recognises the importance of an effective regime to interdict criminal proceeds. The joint note highlights that certain contracts are particularly exposed as vehicles for the proceeds of crime. For example, unit-linked premium contracts, purchase of annuities, life insurance contracts or personal pension contracts. The IAIS introduced measures to combat money laundering and the funding of terrorism in 2002. The steps taken focus on knowing your customer and the need to cooperate with law enforcement bodies. The joint note also highlights the importance of maintaining effective internal controls to ensure that information can be verified and suspicious activities can be reported to the appropriate persons.

The Joint Forum notes the unique ways the securities industry is vulnerable to money laundering, particularly the process of layering the proceeds of crime, which is channelling criminal funds away from their source. Moreover, the securities industry is exposed to the laundering of the proceeds of crime in the following ways. For example, employees acting on behalf of a money launderer; accepting business from persons in jurisdictions with less stringent standards to combat criminal money entering the financial system; and trading schemes that wash dirty money. IOSCO introduced various sets of standards and principles to combat money laundering and the finance of terrorism due to the intricate trading and settlement systems that exist in the securities industry both in the domestic and international context. Therefore, IOSCO has placed responsibility on its individual members to implement effective standards to stop criminal proceeds from entering the securities industry.

The initiatives by the three supervisory committees have centred on measures to ensure the financial industry has systems in place on know-your-customer, which are effective and robust. The joint note also highlights the importance of creating a management culture with specific internal controls to combat money laundering and the financing of terrorism. This requires the three financial sectors to work on a consolidated system of controls in order to ensure that information on a customer is available domestically and internationally across all three financial sectors of a group.

\section{References}

1 The Joint Forum, Initiatives by the BCBS, IAIS and IOSCO to combat money laundering and the financing of terrorism, June (2003) posted at www.bis.org/publ/joint05.pdf

\section{Dr Dalvinder Singh}

Lecturer in Law Oxford Brookes University, IALS Editor, June 2003 